\title{
Data Contamination By Social Desirability Response Bias In Research On Students' Cheating Behavior
}

Richard A. Bernardi, (Email: rbernardi@rwu.edu), Roger Williams University Catherine C. LaCross, (Email: clacross999@rwu.edu), Roger Williams University

\begin{abstract}
Our study examines the effect of social desirability on the model developed by Salter et al. (2001). We believe that social desirability response bias contaminates many of the variables that have been used in previous research modeling academic cheating. We initially examined the effect of variables identified in prior research to demonstrate that our sample is equivalent to those in prior studies. We then examined the effect of social desirability response bias using Paulhus' Image Management Subscale (1986) on their tolerance towards cheating; their cynicism about cheating; and one's acknowledged intention to cheat in the future.
\end{abstract}

\section{Introduction}

$\mathrm{t}$ is not a new phenomenon that scandals and unethical behavior plague the business world. Similar to politics, business has earned the reputation for being an area where people and companies are not particularly bothered by scruples. In fact, most people who hear the words "business" and "ethics" paired together simply laugh and poke fun at the apparent oxymoron. Perhaps this phenomenon should not surprise us given the reported increase in collegiate cheating. Research has shown that cheating behaviors was carried over from high school to college (Bernardi et al., 2004). Unfortunately, given the popularity of the Internet, academic dishonesty is becoming more prevalent on college campuses. For example, The Wall Street Journal (April, 1995) reports that college students believe that:

When you get to college, you don't follow the same rules your parents laid down for you. But we're just taking a break [during college and will] get back to [the rules] later.

However, because an individual's values are established by early life experiences, these values will probably not be altered by future educational experiences (DuPont and Craig, 1996). Consequently, a major concern is that students' attitudes toward cheating may determine their conduct and decisions as managers (Lysonski and Gaidis, 1991). Our study is grounded on Randall and Gibson's (1990) finding that nearly 90 percent of business ethics studies rely on self-reported data, but do not control for social desirability response bias (SDRB). This research examines the effect of SDRB in modeling students' cheating behavior, which Ameen et al. (1996) and Salter et al. did not control for in their research.

\section{Literature Review}

Barnett and Vaicys (2000) found that individuals' ethical judgments associate with their behavioral intentions. Figure 1 shows the basic influences on an individual's decision-making process (Ajzen and Fishbein 1980). This model suggests that, when facing a scenario where these values imply different actions, there might be a conflict between an academic code of conduct and personal values. 
Figure 1. The Influence of Individual Attitudes and Subjective Norms in Decision Making

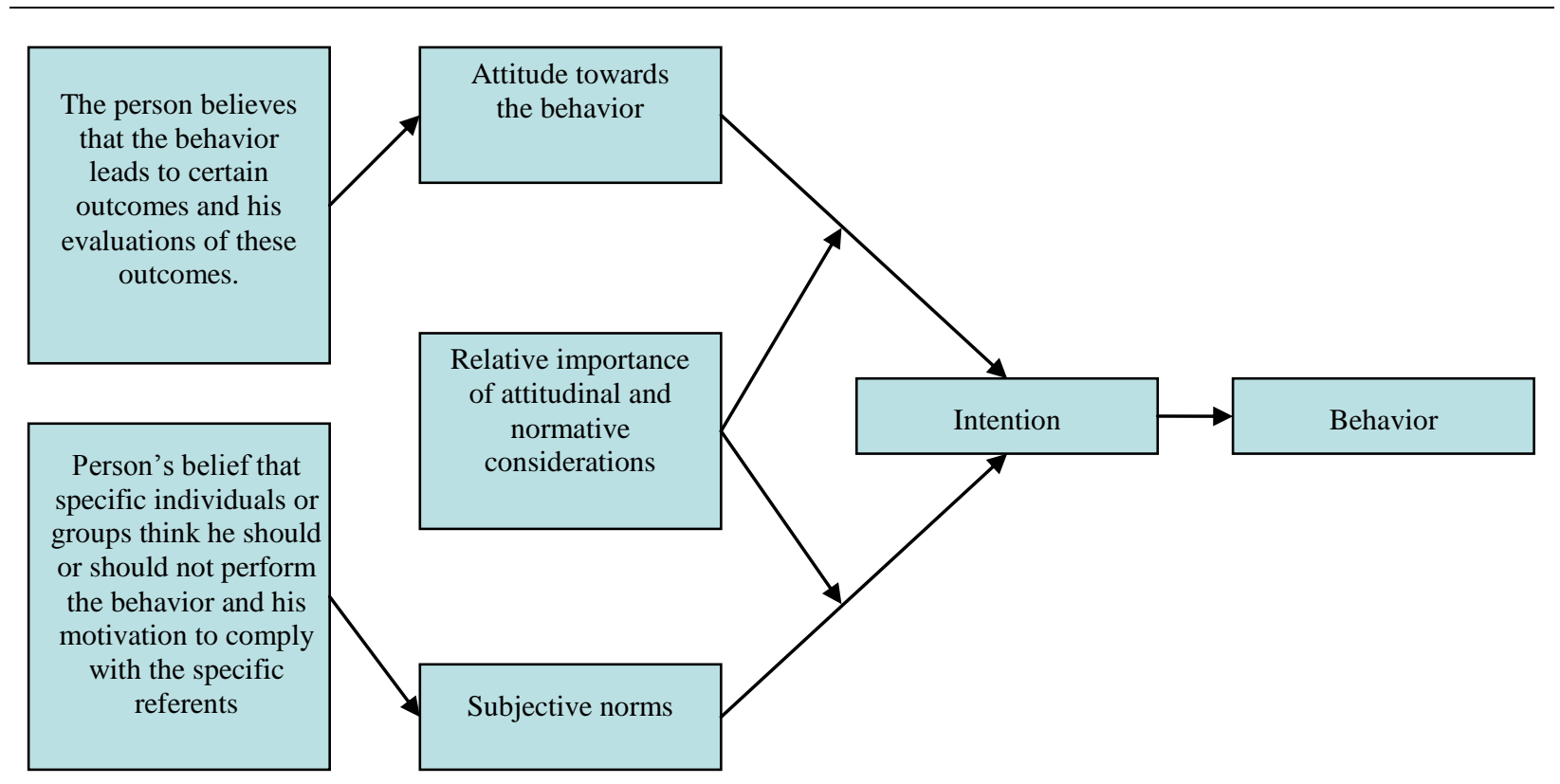

Note: arrows indicate proposed direction of influence. From: Ajzen and Fishbein (1980, p. 8)

Social desirability response bias (SDRB) is the tendency of individuals to respond to questions in a manner that they deem as socially acceptable. For example, if a person wished to be perceived as ethical, they would answer questions they believed achieved that goal regardless of their true beliefs. Chung and Monroe (2003) confirmed that bias was higher when the respondent deemed the action as more ethical (i.e. more desirable) and lower when deemed less ethical (i.e. less desirable). Randall and Fernandes (1991) and Schoderbek and Deshpande (1996) also found a positive association between social desirability and self-reported data to questions on ethics; however, while this is an established phenomenon, less than 10 percent of the studies in ethics control for SDRB (Randall and Gibson, 1990).

We believe that several of the independent variables that were used by Ameen et al. (1996) and Salter et al. (2001) in modeling students' cheating behavior associate with SDRB. Consequently, the literature review focuses on our hypothetical associations between SDRB and Ameen et al. and Salter et al.'s independent variables. In the development of our research hypotheses, we inherently assume that an individual desires to be perceived as behaving ethically, and that desire may lead to socially desirable responding. For instance, one could argue that SDRB influences the responses of students to questions concerning:

1. their self-reported cheating behavior;

2. their tolerance towards cheating;

3. their cynicism about cheating; and,

4. one's acknowledged intention to cheat in the future.

\section{Self-Reported Cheating Behavior}

While the effects of social desirability response bias have been consistently documented in other areas of research using self-reported survey data, social desirability response bias is uniformly ignored or quickly dismissed in cheating research. For instance, in the 14 studies cited in this research, we found only one study ( 7.1 percent) that 
acknowledged the potential for social desirability response bias. Smith et al. (2004, p. 77) dismiss the potential for this type of bias:

[O]ne might presume that respondents under-reported their. . . cheating behaviors and cheating proclivities. However, during the survey administration, proctors explained the nature of the data collection and tabulation process and how it would protect the participants' anonymity. More importantly, however, this study's focus was on the interrelationships among posited constructs within the tested theoretical model, not the mean construct values.

One contention in the research deals with wording questions in the third person rather than in the first person. This line of reasoning maintains that, if one asks questions in the third person, a participant will actually respond with what he/she would do in the situation, which would probably not be the case if the question was asked in the first person. Geiger and O'Connell (2000) tested this hypothesis and controlled for social desirability response bias using Paulhus' complete Balanced Inventory of Desirable Responding $(1984,1991)$. These authors found that social desirable responding still occurred in questions asked in the third person in surveys designed to "protect the participants' anonymity". Social Desirability Response Bias was significant in all three of their dilemmas and explained between 3.4 and 17.2 percent of the variation (adjusted $\mathrm{r}^{2}$ ) in the participants' responses. Geiger and O'Connell's (2000, p. 118) conclude that:

[Using] a surrogate measure of social desirability response bias is less desirable than using a direct measure of this bias such as Paulhus' (1991, 40-41) impression-management subscale scores.

This finding is supported by Bernardi et al.'s (2003) international study; in four of their five scenarios, social desirability response bias was a significant factor. Geiger and O'Connell's (2000, p. 118) research and conclusion about controlling for social desirability response bias provides support for our first research hypothesis:

H1: As social desirability response bias increases, self-reported cheating behavior will decrease.

\section{Tolerance towards Cheating}

Tolerance towards cheating refers to how students view academic dishonesty. Many factors may contribute to college students' decisions to cheat, but the fact that most students lack academic integrity or have a high tolerance for cheating is disturbing (Davis et al., 1992). In Bunn et al.'s (1992) study, over 70 percent of the students surveyed did not believe that cheating was a problem, even though the majority indicated that they did cheat. These researchers believed that students do "not consider cheating a serious offense" (p. 201). Likewise, several studies found an association between students cheating and their attitudes and/or tolerance towards cheating (Jensen et. al., 2002; Jordan, 2001; Whitley et al., 2001). Our second hypothesis suggests the association between social desirability response bias and a student's reported tolerance of cheating.

\section{H2: As social desirability response bias increases, self-reported tolerance toward cheating will decrease.}

\section{Cynicism about Cheating}

Cynicism reflects a basic distrust of human nature and motives; additionally, students think that cheating is the only way to "level the playing field" because of the competition in college (McCabe et al., 2001). For example, Ameen et al. (1996) found that students with a higher level of cynicism are more likely to cheat. In their replication of Ameen et al.'s study, Salter et al. (2001) found similar results. Jordan (2001) notes that academically dishonest (honest) students witness more (less) cheating and believe their peers are cheating more (less) often. Consequently, observing others cheat reinforces one's own cheating behavior. However, while cynicism associates with cheating behavior (Ameen et al., 1996; Salter et al., 2001), an attitude of 'I cheat because others are cheating' would not be seen as a socially desirable response, and our third hypothesis can be stated:

H3: $\quad$ As social desirability response bias increases, self-reported cynicism decreases. 


\section{Intention to Cheat}

One's intention to cheat is a difficult variable to measure and is potentially tainted by the individual's desire to maintain an image of being a "good and honest person" (i.e., image management). Research suggests that, if you ask a person what he/she believes another person would do in a situation, socially desirable responding is minimized (McDonald and Ho, 1995). While a considerable body of research is based on this premise (i.e., the literature in moral development using the Defining Issues Test [Rest, 1979]), there has not been a definitive study supporting this premise. Consequently, our review of the literature is quite constrained.

Bernardi et al. (2004) examined students cheating using a research instrument based on the Defining Issues Test (DIT). In contrast to using the general scenarios in the DIT, the authors constructed and validated a parallel test (i.e., the Academic Honesty Scale [AHS]) that incorporated dilemmas focusing on situations involving the potential temptation to cheat. Rather than asking participants to estimate what the person in each scenario would do on a three-point scale (i.e., cheat, not sure, or do not cheat), the authors used a seven-point Likert scale to measure a student's intentions to act honestly/dishonestly in each scenario. The student's responses on the Likert scales for the three scenarios were summed to compute the Academic Integrity Index (AII), which is an indication of the student's intention to cheat over the three scenarios.

Their data support Graham et al.'s (1994) findings that students' attitudes towards cheating are better at explaining cheating behavior than background variables. While the score on the AII was only marginally significant between students who never cheated and those who only cheated in high school, the AII was highly significant between students who never cheated and those cheated in both high school and college. Consequently, their data suggest that the AII measures an individual's propensity to act honestly in a situation involving the potential for cheating. However, Bernardi et al. did not incorporate a measure of social desirability response bias in their study.

The influence of social desirability response bias has been demonstrated in ethics literature; however, as Randall and Gibson (1990) note, only a small percentage of published research controls for this bias. In an international study involving students from ten countries, Bernardi et al. (2003) found a consistent significance of social desirability response bias in responses to ethical dilemmas was significant in the models of four of their five scenarios. Their findings suggest that conclusions drawn from research need to be adjusted for the level of social desirability response bias of different cultures.

H4: $\quad$ As social desirable responding increases, the self-reported intentions to cheat in the future will decrease.

\section{Gender and Cheating}

A common finding in most research is that women are more ethically sensitive than men. For instance, Swamy et al. (2001) found that women were significantly more likely to categorize a given corrupt action as "never justified" than were men. In their research, Bernardi and Arnold (1997) found that women scored higher on the DIT (Rest's Defining Issues Test) indicating that women are more ethically sensitive than are men. Jensen et al. (2002) found that men are more likely to cheat than women. However, Whitley (2001, p. 250) discovered that female college students "hold more negative attitudes toward cheating than do [male college students] but are about equally likely to cheat." Women are also more likely to respond in a socially desirable manner (Bernardi et al., 2003; Jensen et al, 2002; Schoderbek and Deshpande, 1996). Consequently, we control for gender in this research.

\section{Methodology}

Subjects

Our sample included 174 responses of which 101 (58.1 percent) were from male and 73 (41.9 percent) were from female business majors. Our research instrument consisted of the Impression Management questionnaire (Paulus 1986), a brief background questionnaire, and the same research instrument used by Salter et al. (Appendix). The surveys were given out during class time and were administered by a student who told the participants that 
faculty would not see any of the completed surveys. The student also told the participants that the faculty member doing the research would only be provided with an Excel file with that contained the survey data. No indication of the student's name was included on the survey instrument and the forms indicating the willingness to participate in the research were collected separately from the remaining data.

\section{Variables}

We use the same variables in this research that were used in three prior studies on cheating behavior (Salter et al., 2001; Ameen et al., 1996; Sierles et al., 1980), which are shown in Table 1. Unlike prior studies, our research specifically examines the potential contamination of prior models by social desirability response bias. To control for this factor, we used the Impression Management Subscale (IMS) of Paulhus' (1986) Balanced Inventory of Desirable Responding (BIDR). The impression management portion of the BIDR is a 20 -item subscale that had the overall highest correlation with seven other social desirability measures reported by Randall and Fernandes (1991). As shown in Table 1, the average score on the IMS was 5.1; female (male) participants' average score was 5.7 (4.6). Equally important, the data in Table 1 also indicate that the current sample is very similar to Salter et al.'s data.

Table 1. Variables and Hypothesized Relationship to Cheating

\begin{tabular}{|c|c|c|c|c|}
\hline Variable & Description of Variable & $\begin{array}{l}\text { Current } \\
\text { Data }\end{array}$ & $\begin{array}{l}\text { Salter } \\
\text { et al. } \\
(2000)\end{array}$ & $\begin{array}{l}\text { Relates with } \\
\text { Cheat1/2 }\end{array}$ \\
\hline Cheat1 & $\begin{array}{l}\text { Level of cheating behavior (sum of four questions concerning } \\
\text { cheating (range: } 0 \text { to } 4 \text { ) }\end{array}$ & 1.18 & NA & NA \\
\hline Cheat2 & $\begin{array}{l}\text { Indicator variable: student had cheated (1) or not cheated }(0)- \\
\text { Cheat } 1 \text { has a value of } 1 \text { or more (i.e., dependent variable in } \\
\text { prior studies) }\end{array}$ & 0.62 & .56 & NA \\
\hline Cynicism & $\begin{array}{l}\text { Average of each student's response for the three questions on } \\
\text { cynicism (range: } 0 \text { to } 5 \text { ) }\end{array}$ & 2.71 & 2.41 & Positive \\
\hline Environment & $\begin{array}{l}\text { Dummy variable; } 1(0) \text { if student had (not) witnessed another } \\
\text { student cheating on an exam. If students continually see other } \\
\text { students not getting caught, this perception could lead them to } \\
\text { cheat. }\end{array}$ & 0.92 & .82 & Positive \\
\hline Gender & Indicator Variable: Males (1) Females (0) & NA & NA & Positive \\
\hline IMS & $\begin{array}{l}\text { Image Management Subscale - a measure of social desirability } \\
\text { response bias (Paulhus, 1986) }\end{array}$ & 5.09 & NA & Negative \\
\hline Intent & $\begin{array}{l}\text { Indicator variable about whether student expected to cheat (1) } \\
\text { or not cheat }(0) \text { in the future. }\end{array}$ & 0.43 & .20 & Positive \\
\hline Punishment & $\begin{array}{l}\text { This relates to question dealing with getting caught cheating. } \\
\text { Valued at } 1(0) \text { for the two most (three least) severe penalties. }\end{array}$ & 0.51 & .46 & Negative \\
\hline Intolerance & $\begin{array}{l}\text { Average of each student's responses to the } 23 \text { questionable } \\
\text { academic practices. Higher averages indicate a lower tolerance } \\
\text { for cheating (range: } 0 \text { to } 5 \text { ) }\end{array}$ & 3.08 & 3.34 & Negative \\
\hline
\end{tabular}




\section{DATA ANALYSIS}

\section{Overview}

Our analysis will model the cheating behavior of our sample to show that our data provide a similar model to what previous research reported. We believe that this demonstrates that our data is similar to the data in prior studies (i.e., ours is not a rogue sample composed of outlier data). Consequently, an association of our model's variables with social desirability response bias can probably be attributed to the variables in the models reported in prior research.

\section{Cheating Behavior and Social Desirability Response Bias}

As indicated in Table 1, we use two measures of cheating behavior. CHEAT1 is the sum of four cheating behaviors reported by our participants: cheating on a major or minor test and cheating on a major or minor project. CHEAT2 is a dichotomous variable and is coded 1 if CHEAT1 was any value other than zero (e.g., the participant had cheated on any one or a combination of our four behaviors) or 0 if the participant had not cheated. Our models for both CHEAT1 and CHEAT2 are shown in Table 2.

Table 2. Regression Models for Cheating Behavior

\section{PANEL A: Model for Cheat1 (Sum of Behaviors)}

$\begin{array}{lccc}\text { Model } & \frac{\text { Adj Rsquare }}{\text { Regression }} & \frac{\text { F Factor }}{27.73} & \underline{\text { Significance }} \\ \text { Term } & 0.331 & & 0.0001 \\ \text { Intercept } & \frac{\text { Coefficient }}{2.06} & \frac{\text { T Stat }}{6.05} & \underline{\text { P-value }} \\ \text { Intent } & 0.48 & 5.64 & 0.0001 \\ \text { Intolerance } & -0.34 & -3.37 & 0.0001 \\ \text { Environment } & 0.30 & -2.14 & 0.0009 \\ & & & 0.0034\end{array}$

PANEL B: Model for Cheat2 (Yes/No)

\begin{tabular}{|c|c|c|c|}
\hline Model & $\underline{\text { Rsquare }}$ & Chi Square & $\frac{\text { Prob }>\text { ChiSq }}{0.0001}$ \\
\hline Regression & 0.260 & 59.62 & 0.0001 \\
\hline Term & Coefficient & Chi Square & Prob $>$ ChiSg \\
\hline Intercept & -1.58 & 2.92 & 0.0872 \\
\hline Intent & -1.05 & 21.22 & 0.0001 \\
\hline Intolerance & 0.56 & 4.36 & 0.0368 \\
\hline Environment & -1.16 & 6.62 & 0.0101 \\
\hline
\end{tabular}

Our first model is for CHEAT1, which was not a measure of cheating behavior that other research reported examining. However, we believe it is as important to examine because CHEAT2 only reflects whether or not the student had cheated. The model for CHEAT1 (Panel A of Table 2) indicates that a student's INTENT to cheat in the future was the most significant predictor of the prior cheating behavior. The other two variables that were significant in the model were INTOLERANCE and ENVIRONMENT, which are also variables reported in prior research. The model explains one third of the variation (adjusted $\mathrm{r}^{2}$ ) of our data. While our measure of social desirability response bias (IMS) was not significant in the model for CHEAT1, in a univariate model, it was significant $(\mathrm{p}<.0001)$.

Our dependent variable CHEAT2 is an indicator variable that reflects whether a student cheated in the past (1) or not cheated (0); consequently, we used a logistic regression model in this part of the analysis. The model for 
CHEAT2 (Panel B of Table 2) indicates that a student's INTENT to cheat in the future was also the most significant predictor of the prior cheating behavior. INTOLERANCE and ENVIRONMENT were also significant in this model and in prior research. The model explains 26.0 percent of the variation (adjusted $\mathrm{r}^{2}$ ) of our data. While our measure of social desirability response bias (IMS) was also not significant in the model for CHEAT2; in a univariate model, it was significant $(\mathrm{p}<.0005)$. Again, we provide these analyses because they demonstrate the similarity of our data with the data in prior research.

We also examined our data for CHEAT1 and CHEAT2 and social desirability response bias using contingency analysis. ${ }^{2}$ Our assumption in this part of the analysis is that if cheating behavior is not affected by socially desirable responding, then the reported cheating behavior (either CHEAT1 or CHEAT2) should be uniformly distributed throughout the levels of the IMS variable. To demonstrate this analysis, we will first analyze the data for the PUNISH and ENVIRONMENT variables. The data in Table 3 indicate that our assumption of an even distribution of responses (i.e., nearly equal expected values for each IMS group) is correct for the PUNISH and ENVIRONMENT variables for each social desirability response bias group.

Table 3. Punishment and Environment by Response Bias

\section{Range of IMS}

Low IMS Group

Observed Frequency

Expected Frequency

Medium IMS Group

Observed Frequency

Expected Frequency

High IMS Group

Observed Frequency

Expected Frequency

\section{Range of IMS}

Low IMS Group

Observed Frequency

Expected Frequency

Medium IMS Group

Observed Frequency

Expected Frequency

High IMS Group

Observed Frequency

Expected Frequency

\section{PANEL A: Punishment as a Percent}

Men

63.1

66.5

67.8

66.5

67.6

66.5

PANEL B: Environment as a Percent

Men

21.4

23.8

24.5

23.8

21.7

23.8
Women

69.0

69.9

70.7

69.9

69.6

69.9

\begin{tabular}{lc}
\hline Low Group & 0 to 2 (men)/0 to 3 (women) \\
Medium Group & 3 to 6 (men)/4 to 7 (women) \\
High Group & Above $6(\mathrm{M}) /$ Above 7 (W) \\
\hline
\end{tabular}

We expressed CHEAT1 as a percentage of the total possible cheating behaviors; the total possible score on CHEAT1 was four because there were four possible opportunities to cheat (Table 1). For example had all 
Contamination of Measures by Social Desirability Response Bias

The data in Table 5 show the models for INTOLERANCE of cheating (Panel A) and CYNICISM about cheating (Panel B). As indicated in Panel A, a student's prior cheating behavior (CHEAT1) was the most powerful variable in their willingness to TOLERATE cheating. Social desirability response bias (IMS) was the only other significant variable in the model and explains 6.7 percent of the variation in INTOLERANCE of cheating.

Table 5. Regression Models for Intolerance and Cynicism

\begin{tabular}{|c|c|c|c|}
\hline \multicolumn{4}{|c|}{ PANEL A: Model for Intolerance of Cheating. } \\
\hline Model & Adj Rsquare & $\underline{\text { F Factor }}$ & $\underline{\text { Significance }}$ \\
\hline$\overline{\text { Regression }}$ & 0.230 & 14.00 & 0.0001 \\
\hline Term & $\underline{\text { Coefficient }}$ & T Stat & $\underline{\text { P-value }}$ \\
\hline Intercept & 2.93 & 21.38 & 0.0001 \\
\hline Cheat1 & -0.22 & -4.58 & 0.0001 \\
\hline IMS & 0.08 & 4.08 & 0.0001 \\
\hline \multicolumn{4}{|c|}{ PANEL B: Model for Cynicism about Cheating } \\
\hline Model & Adj Rsquare & $\underline{\text { F Factor }}$ & $\underline{\text { Significance }}$ \\
\hline$\overline{\text { Regression }}$ & 0.132 & 19.00 & 0.0001 \\
\hline Term & $\underline{\text { Coefficient }}$ & T Stat & $\underline{\mathrm{P} \text {-value }}$ \\
\hline$\overline{\text { Intercept }}$ & 3.00 & $\overline{16.83}$ & $\overline{0.0001}$ \\
\hline Intent & -0.41 & -4.30 & 0.0001 \\
\hline IMS & -0.05 & -2.93 & 0.0848 \\
\hline IMS & The Image $\mathrm{M}$ & tt Subscal & \\
\hline
\end{tabular}

For our CYNICISM model (Panel B), our data indicate that a student's INTENT to cheat in the future was the most significant variable and that IMS was marginally significant. As one would anticipate, as socially desirable responding increased, one's INTOLERANCE for cheating increased (e.g., IMS has a positive sign in Panel A). However, as socially desirable responding increased, ones CYNICISM about cheating decreased (e.g., IMS has a negative sign in Panel B), which one would also anticipate.

Table 6. Contingency Analysis for Intention to Cheat by Response Bias

\begin{tabular}{|c|c|c|}
\hline Range of IMS & Men & Women \\
\hline \multicolumn{3}{|l|}{ Low IMS Group } \\
\hline Observed Frequency & 77.8 & 50.0 \\
\hline Expected Frequency & 49.0 & 34.7 \\
\hline \multicolumn{3}{|l|}{ Medium IMS Group } \\
\hline Observed Frequency & 45.1 & 33.0 \\
\hline Expected Frequency & 49.0 & 34.7 \\
\hline \multicolumn{3}{|l|}{ High IMS Group } \\
\hline Observed Frequency & 22.7 & 22.7 \\
\hline Expected Frequency & 49.0 & 34.7 \\
\hline Low Group & 0 to 2 (men)/0 to 3 (women) & \\
\hline Medium Group & 3 to 6 (men)/4 to 7 (women) & \\
\hline High Group & Above $6(\mathrm{M}) /$ Above $7(\mathrm{~W})$ & \\
\hline
\end{tabular}


We also used a contingency-analysis approach to demonstrate the lack of independence of our INTENT to cheat in the future. Our assumption for this variable is the same as for CHEAT1 and CHEAT2; if this variable is not affected by socially desirable responding, then its reported values should be uniformly distributed throughout the levels of the IMS variable. For INTENT of cheat in the future, we would anticipate a 49.0 (34.7) percent uniform value throughout the range of IMS groups. The data in Table 6 indicate that our expectation was only correct for the middle group for both male and female students. The data indicate that the lowest IMS groups reported a higher percentage of intention to cheat in the future than the highest IMS groups. The hypothesis that INTENT is independent of social desirable response bias can be rejected $\left(X^{2}=42.3, \mathrm{p}<.0005\right)$.

\section{Conclusions}

This research set out to determine whether an individuals' level of social desirability response bias associates with several of the variables included in prior research on student cheating. Our analysis indicates that our data were similar to the data used by Salter et al. (2001) for the students from the United States as it relates to the model for cheating behavior. Our analysis also indicates that the self-reported cheating behavior of students is contaminated by social desirability response bias. We also demonstrate that several of the independent variables considered in prior research (i.e., Intolerance of cheating, cynicism about cheating, and intent to cheat in the future) are also contaminated by social desirability response bias.

Our data echo the caution of Randall and Gibson (1990) that, even though self-reported data were used in 90 percent of business ethics research since 1960, only one out of 96 articles considered social desirability response bias as part of their research design. Our Image management Subscale data were consistently significant for the dependent and independent variables studied. Our analysis suggests that future research needs to include a measure of social desirability response bias in the research methodology.

Not addressed to this point is whether to include social desirability response bias as an independent variable or to standardize (i.e., adjust) the variables considered in the research by social desirability response bias. However, this debate was not the purpose of this research, but it does suggest an interesting subject for future research. While one study does not conclusively prove an association among variables, we believe that this is the first research to show that the existing research on student cheating needs to be reexamined for social desirability response bias.

There are three apparent limitations in our research. The first limitation is that the sample comes from only one university and should be expanded to examine a broader base. Second, we only examined the attitudes of business majors, future research should expand our sample to include majors outside of business. Finally, we used Paulhus' measure of social desirability response bias; other measures should be used in future research.

\section{Endnotes}

1. The lead and second authors collaborate on many research projects and alternate lead author responsibilities. Both authors contribute equally to all of their joint works.

2. We added the contingency analysis for the CHEAT1 and CHEAT2 variables because we believe it is a better (more visual) depiction of our results.

3. Because of differences in the distributions of the IMS variable, we had to use different cutoffs for male and female students. We also changed these cutoff points to see if our choice of groupings made a difference in our analysis; the results remained the same regardless of grouping cutoff.

\section{References}

1. Ajzen, Icek., and Martin Fishbein. "Understanding Attitudes and Predicting Social Behavior", Englewood Cliffs, NJ: Prentice-Hall. 1980.

2. Ameen, Elsie C., Daryl M. Guffey and Jeffery J. McMillan. "Accounting students' perceptions of questionable academic practices and factors affecting their propensity to cheat," Accounting Education, Vol. 5 (3), pp. 191-205, 1996. 
3. Barnett, Tim, and Vaicys, Cheryl. "The Moderating Effect of Individuals' Perceptions of Ethical Work Climate on Ethical Judgments and Behavioral Intentions," Journal of Business Ethics, Vol. 27 (4), 351-362, 2000.

4. Bernardi, Richard A., Rene L. Metzger, Ryann G. Scofield-Bruno, Marisa A. Wade-Hoogkamp, Lillian E. Reyes, and Gary H. Barnaby. "Examining the Decision Process of Students' Cheating Behavior: An Exploratory Study," Journal of Business Ethics, 50 (4), 392-414.

5. Bernardi, Richard A., and Donald F. Arnold, Sr., "An Examination of Moral Development within Public Accounting by Gender, Staff Level, and Firm," Contemporary Accounting Research, Vol. 14 (4), pp. 653668, 1997.

6. Bernardi, Richard A., Erin L. Delorey, Catherine C. LaCross, and Rebecca A. Waite. "Evidence of Social Desirability Response Bias in Ethics Research: An International Study" The Journal of Applied Business Research. Vol. 19 (3), pp. 41-51, 2003.

7. Berton, L. (1995). "Business Students Hope to Cheat and Prosper, A New Study Shows," The Wall Street Journal, April 25, 1995. p. B-1.

8. Bunn, Douglas N., Steven B. Caudill, and Daniel M. Gropper. "Crime in the Classroom: An Economic Analysis of Undergraduate Student Cheating Behavior," Research in Economic Education, Summer, 1992.

9. $\quad$ Chung, Janne, and Gare Monroe. "Exploring social desirability bias," Journal of Business Ethics, Vol. 44 (4), pp. 291-302, 2003.

10. Davis, Stephen F., Cathy A. Grover, Angela H. Becker, Loretta N. McGregor. "Academic Dishonesty: Prevalence, Determinants, Techniques, and Punishments," Teaching of Psychology, Vol. 19 (1), pp. 16-20, 1992.

11. DuPont, Ann M. and Jane S. Craig. "Does Management Experience Change the Ethical Perceptions of Retail Professionals: A Comparison of the Ethical Perceptions of Current Students with those of Recent Graduates?” Journal of Business Ethics, Vol. 15 (8), pp. 815-826, 1996.

12. Geiger, Marshall A. and Brendan T. O'Connell. "An Examination of Using Surrogate Measures to Assess Social Desirability Response Bias," Research on Accounting Ethics, Vol. 6, pp. 107-120, 2000.

13. Graham, Melody A., Jennifer Monday, Kimberly O'Brien and Stacy Steffen: "Cheating at Small Colleges: An Examination of Student and Faculty Attitudes and Behaviors," Journal of College Student Development, Vol. 35 (4), pp. 255-260, 1994

14. Jensen, Lene A., Jeffrey J. Arnett, S. Shirley Feldman, and Elizabeth Cauffman. "It's Wrong But Everybody Does It: Academic Dishonesty among High School and College Students," Contemporary Educational Psychology, Vol. 22, pp. 209-222, 2002.

15. Jordan, Augustus E., "College Student Cheating: The Role of Motivation, Perceived Norms, Attitudes, and Knowledge of Institutional Policy," Ethics \& Behavior, Vol. 11 (3), pp. 233-247, 2001.

16. Lysonski, Steven and William Gaidis. "A Cross-Cultural Comparison of the Ethics of Business Students," Journal of Business Ethics, Vol. 10 (2), pp. 141-150, 1991.

17. McCabe, Donald L., Linda K. Treviño, and Kenneth D. Butterfield. "Cheating in Academic Institutions: A Decade of Research," Ethics \& Behavior, Vol. 11 (3), pp. 219-232, 2001.

18. McDonald and Ho, "Questioning Techniques and Social Desirability Response Bias in Ethical Scenarios," Working paper State University of New York at Albany, 1995.

19. Paulhus, Delroy L., "Two-Component Models of Socially Desirable Responding," Journal of Personality and Social Psychology Vol. 46, pp. 598-609, 1984.

20. Paulhus, Delroy L., "Self-Deception and Impression Management in Test Responses," pp. 17-41, in A. Angleiter and J. S. Wiggins (Eds.), Personality Assessment via Questionnaire: Current Issues in Theory and Measurement, Springer-Verlag, Berlin, Germany, 1986.

21. Paulhus, Delroy L., "Balanced Inventory of Desirable Responding (BIDR)," Vol. 1, pp. 37-41, in J. P. Robinson, P. R. Shaver, and L. S. Wrightsman (Eds.), Measures of Personality and Psychological Attitudes, Academic Press, New York, 1991.

22. Randall, Donna M., and Maria F. Fernandes, "The Social Desirability Response Bias in Ethics Research," Journal of Business Ethics, Vol. 10 (11), pp. 805-817, 1991.

23. Randall, Donna M., and Annetta M. Gibson, "Methodology in Business Ethics Research: A Review and Critical Assessment," Journal of Business Ethics, Vol. 9 (6), pp. 457-472, 1990. 
24. Rest, James R., Defining Issues Test, Center for the Study of Ethical Development, University of Minnesota Press, Minneapolis, MN, 1979.

25. Salter, Stephen B., Daryl M. Guffey, and Jeffrey J. McMillan. "Truth, Consequences and Culture: A Comparative Examination of Cheating and Attitudes about Cheating among U.S. and U.K. Students," Journal of Business Ethics, Vol. 31 (1), pp. 37-50, 2001.

26. Schroderbek, Peter P. and Satish P. Deshpande. "Impression Management, Overclaiming, and Perceived Unethical Conduct: The Role of Male and Female Managers," Journal of Business Ethics, Vol. 15 (4), pp. 409-414, 1996.

27. Sierles, F., I. Hendrickx, and S. Circle. "Cheating in Medical School," Journal of Medical Education, Vol. 55: pp. 124-125, 1980.

28. Smith, Kenneth J., Jeanette. A. Davy, and Debbie Easterling. "An Examination of cheating and Its Antecedents among Marketing and Management Majors," Journal of Business Ethics, Vol. 50 (1), pp. 6380, 2004.

29. Swamy, Anand, Stephen Knack, Young Lee, and Omar Azfar, "Gender and Corruption," Journal of Development Economics, Vol. 64 (1), pp. 25-55, 2001.

30. Whitley Bernard E., Jr. "Gender Differences in Affective Responses to Having Cheated: The Mediating Role of Attitudes," Ethics \& Behavior, Vol. 11 (3), pp. 235-274, 2001.

\section{Appendix}

\section{Survey Questions By Category}

\section{Questionable Academic Practices Questions}

1. Looking at another student's exam during tests.

2. Using unauthorized "crib" notes during an exam.

3. Borrowing another person's speech, report, or paper and presenting it as one's own work.

4. Having someone else write a speech, report, or paper for you after you have done the basic research.

5. Rephrasing words or ideas from a book, journal, or magazine and presenting them without giving their source.

6. Asking someone who has already taken an exam what the questions are.

7. Asking someone for the answers during an exam.

8. Exchanging papers during an exam.

9. Writing a speech, report, paper, etc., for someone else.

10. Lying to an instructor about illness, etc., when an exam or assignment is due.

11. Failing to report grading errors when the professor has not approved ignoring errors in the student's favor.

12. Copying homework from another student.

13. Studying from someone else's notes without their approval.

14. Not contributing one's fair share in a group project for which all the members will be given the same grade.

15. Falsifying or fabricating a bibliography.

16. Visiting a professor after an exam with the sole intention of biasing one's exam grade.

17. Taking a test for a friend.

18. Obtaining a copy of the exam prior to taking it in class.

19. Obtaining an old test from a fraternity / sorority file or from a student who took the class in a previous semester when the professor has expressly prohibited the release of old tests.

20. Giving answers to someone else during an exam.

21. Turning in work or a paper purchased from a fellow student or a commercial research firm.

22. Arranging to sit next to someone in order to copy off that individual's test paper.

23. Bribing or blackmailing a fellow student or a professor to provide unauthorized assistance.

\section{Deterrent Value of Possible Punishment Questions}

1. Knowing that the order of the questions is scrambled on versions of a multiple choice test.

2. Knowing that the multiple choice answers as well as the questions were scrambled on versions of the test.

3. Giving problems / short answers / essay questions instead of multiple choice questions.

4. Knowing that the given information for problem / short answer questions is not the same on all test versions.

\section{Cynicism Questions}

1. People who say they have never cheated before are hypocrites. 
2. Everybody steals, cheats, or lies at least once in his/her lifetime.

3. People have to cheat in this "dog-eat-dog" world.

\section{Personal Experience Questions}

1. Have you ever observed another student cheating on an exam?

2. Have you ever observed another student cheating on a project or a written assignment?

3. Have you ever seen another student get caught cheating?

4. Do you know anyone who routinely cheats on exams?

5. Have you ever cheated on a major exam ( $20 \%$ or more of the final grade)?

6. Have you ever cheated on a minor exam (less than $20 \%$ of the final grade)?

7. Have you ever cheated on a major project or assignment ( $20 \%$ or more of the final grade)?

8. Have you ever cheated on a minor project or assignment (less than $20 \%$ of the final grade)?

9. Do you think you will cheat in the future?

10. Have you ever been caught cheating?

11. Based on your experience in large sections where multiple-choice testing is used, what percentage of students do you think cheat on a typical exam?

12. If you are caught cheating on an exam, what would you expect to happen?

13. If you are caught cheating on a project or written assignment, what would you expect to happen?

14. Of the cheating you have observed, what percentage do you think was "panic" cheating and what percentage do you think was "premeditated." While panic cheating is not planned, premeditated cheating is planned in advance of the test.

15. In your opinion, cheating at the university level is:

16. Do you think more should be done to stop cheating?

17. Do you believe cheating is a direct result of the competition for grades?

18. Do you believe cheating is wrong, dishonest, or unethical?

19. Describe the most common method of cheating you have observed in college.

20. Describe the most unusual or creative form of cheating you have observed in college.

21. What do you feel would be an effective way to deter cheating? 
Notes 